\title{
PERCEPÇÃO ARBORIZAÇÃO URBANA - MORADORES DE REGISTRO, NO ESTADO DE SÃO PAULO
}

\author{
CITIZENS' PERCEPTION ON THE URBAN AFFORESTATION OF REGISTRO IN SÃO \\ PAULO STATE
}

\author{
Luis Carlos Ferreira de Almeidaํ, Marcelo Vieira Ferraz², Letícia Gutierrez Cecília ${ }^{3}$
}

\section{RESUMO}

O objetivo deste trabalho foi avaliar a percepção dos moradores de Registro-SP sobre a arborização urbana. Foi elaborado um questionário, utilizando-se como base a Escala de Likert, que consiste em uma escala de cinco pontos com um ponto médio para registro de uma situação intermediária ou de nulidade. A pesquisa foi realizada no mês de setembro de 2015, sendo desenvolvida em duas etapas. Na primeira etapa ocorreu a aplicação de 40 questionários a partir dos quais foi possível estimar o tamanho da amostra em 88 questionários para um erro máximo de 10\% e 95\% de probabilidade, constituindo-se a aplicação dos 48 questionários restantes na segunda etapa da pesquisa. Foram aplicadas estatísticas descritivas e testes de comparação de médias, com análise multivariada de dados, finalizando a partir das variáveis com as maiores correlações com um teste de qui-quadrado para verificar como se dá a relação de dependências entre elas. Concluiu-se que a maioria é a favor do plantio de árvores, sendo contra a sua retirada após o plantio, porém o risco de erro na arborização é alto uma vez que a população foi a responsável pelo plantio das mudas. A maioria percebeu que a cidade é pouco arborizada.

Palavras-chave: Árvores; Floresta urbana; Meio ambiente; Paisagismo; Verde urbano.

\begin{abstract}
The objective of this study was to evaluate the perception of the residents of Registro-SP about the urban afforestation. A questionnaire was drawn up using the Likert Scale, which consists of a five-point scale with a midpoint for recording an intermediate or null situation. The research was carried out in October 2014, being developed in two stages. In the first stage, 40 questionnaires were used, from which it was possible to estimate the sample size in 88 questionnaires for a maximum error of $10 \%$ and $95 \%$ probability, and the remaining 48 questionnaires were applied in the second step of the research. Descriptive statistics and comparison tests of means with multivariate data analysis were applied, ending from the variables with the highest correlations with a chi-square test to verify how the dependence relation between them occurs. It was concluded that the majority of the population like to planting trees, being against their withdrawal after planting, but the risk of error in the afforestation is high since the population was responsible for planting trees. The major of the population have the sensibility that the city does not have much trees along the streets.
\end{abstract}

Keywords: Trees; Urban forest; Environment; Landscaping; Urban Green.

Recebido em 16.08.2019 e aceito em 22.10.2019

1 Engenheiro Agrônomo. Professor Assistente Doutor da UNESP. Registro/SP. Email: luis.almeida@unesp.br

2 Engenheiro Agrônomo. Professor Assistente Doutor da UNESP. Registro/SP. Email: marcelo.ferraz@unesp.br

3 Graduanda. Discente da UNESP. Registro/SP. Email: lelegutierrz@gmail.com 


\section{INTRODUÇÃO}

Um dos graves problemas enfrentados nas cidades brasileiras é a falta de áreas verdes como praças, jardins e, principalmente, uma arborização adequada. Segundo Maria, Biondi e Brobowski (2016) as áreas urbanas estão cada vez mais insalubres pela perda da vegetação, o que acaba influenciando o conforto e saúde de seus moradores. Nas cidades onde ocorre o planejamento urbano o conforto térmico tem evitado prejuízos para a saúde das pessoas e para o ambiente (SILVA et al., 2016).

Os municípios brasileiros são muito desiguais em relação a distribuição do verde urbano, havendo uma disparidade entre bairros no que diz respeito a arborização urbana. Segundo Lourenço et al. (2016), na cidade de São Paulo essa discrepância fica evidente em termos de índice de cobertura vegetal, por exemplo, o bairro do Itaim Paulista possui um índice de 2,24 $\mathrm{m}^{2} /$ habitante, contrastando com o bairro do Jaçanã com 151,31 $\mathrm{m}^{2} /$ habitante.

Arborizar uma cidade requer planejamento que deve ser elaborado por uma equipe multidisciplinar, considerando que iniciativas tanto do poder público quanto de particulares em promover a arborização de ruas, quando conduzidas inadequadamente produzem, ao final, resultados negativos. Não são raros os casos de árvores que durante o seu desenvolvimento irão prejudicar a mobilidade de pessoas e veículos além de colocarem em risco redes elétrica e de telefonia

Árvores trazem uma série de benefícios, no entanto, quando implantadas de forma inadequada devido à falta de planejamento podem trazer prejuízos e transtornos para a população como: interrupção no fornecimento de energia elétrica, entupimento de redes de esgoto e/ou pluvial, danos a edificações, obstáculos para circulação e acidentes envolvendo pedestres e veículos (RECH; MARTINS, 2016).

Percepções negativas da arborização em detrimento aos benefícios, podem estimular situações nas quais o próprio morador pode se posicionar contrário ao seu plantio. Rodriges, Malafaia e Queiroz (2010) ao avaliarem como a população de Pires do Rio (GO) a percepção sobre a arborização desta cidade, identificaram que os moradores não percebiam a sua importância no contexto urbano apresentando respostas contraditórias quanto aos seus benefícios.

Segundo Tonetti, Biondi e Leite (2016), a percepção ambiental humana é complexa sendo necessário conhecer o contexto de criação, educação, herança genética e os arredores físicos onde cada indivíduo convive. Para Zem e Biondi (2014) a percepção e o comportamento humano podem influenciar na conservação da natureza. Wanderley et al. (2017) citam que devem ser realizado o levantamento da percepção dos moradores para que o planejamento e manejo da 
arborização venham atingir as necessidades sociais, ambientais, paisagísticas e de sustentabilidade.

Dessa forma, o presente trabalho teve como objetivo avaliar a percepção dos moradores da área urbana da cidade de Registro- SP acerca de como estes avaliam a arborização urbana existente no município.

\section{MATERIAL E MÉTODOS}

A cidade de Registro está situada no Vale do Ribeira no Estado de São Paulo. O Município conta com área de $722,201 \mathrm{Km}^{2}$, dos quais $78,54 \mathrm{Km}^{2}$ são urbanos. Possui uma população de 56.322 habitantes, sendo 48.169 na cidade e 6.092 na zona rural (IBGE, 2019). A cidade tem clima quente e úmido, com temperatura máxima de $35^{\circ} \mathrm{C}$, mínima de $13^{\circ} \mathrm{Cea}$ média anual de $24^{\circ} \mathrm{C}$. a cidade está inserida na grande região do bioma Mata Atlântica da Floresta Ombrófila Densa. A umidade relativa do ar é de 84\% (média anual), com Índice pluviométrico de 1500 mm (média anual) e apresenta 1600 horas de sol (média anual). O município está a uma altitude de $15 \mathrm{~m}$ acima do nível do mar, sendo dividido pelo Rio Ribeira do Iguape com economia baseada na Agricultura, pecuária, indústria de beneficiamento e comércio (FERRAZ; NOGUEIRA, 2009).

Para obtenção dos dados elaborou-se um questionário onde foram selecionados parâmetros que pudessem ser objetivamente avaliados pelos respondentes quanto a sua percepção sobre o tema. Inicialmente os entrevistados responderam questões como sexo, idade, escolaridade, conhecimento da arborização em frente à sua residência; opinião a respeito da arborização atualmente na cidade e do conhecimento das responsabilidades institucionais sobe as árvores já existentes.

Uma das estratégias propostas para mensurar esse fenômeno qualitativo (percepção) foi o uso o uso da Escala de Likert, que consiste normalmente em uma escala de cinco pontos com um ponto médio para registro de uma situação intermediária ou de nulidade. Segundo Pereira (2004) essa escala tornou-se um paradigma da mensuração qualitativa, quer na forma original quer em adaptações para diferentes objetos de estudo, ainda segundo esse autor o sucesso do uso dessa escala reside no fato que ela tem a sensibilidade de reconhecer a oposição entre os contrários, gradiente e, em dadas situações, reconhecer a situação intermediária.

Uma questão importante, referente à construção desse tipo de escala, é a definição do número apropriado de categorias para mensuração de um fenômeno. Brandão e Bahry (2005), sugerem a utilização de escalas com, no mínimo, 4 e, no máximo, 10 intervalos, alegando que, com escalas com menos de 4 pontos, pode não haver diferenciação satisfatória e, com mais de 
10 pontos, as pessoas podem ter dificuldade para responder. Se o número de intervalos for ímpar, por sua vez, torna-se possível atribuir uma resposta neutra; se for par, não se admite a neutralidade.

Com base nestes parâmetros, foi construída uma escala com quatro pontos com as seguintes categorias, Concordo, Concordo na maior parte, Discordo na maior parte e Discordo, não cabendo ao respondente uma posição neutra como avaliador, pois sendo a sua participação voluntária pressupõe-se que esse respondente tenha uma opinião sobre o meio que o circunda.

A pesquisa foi realizada no mês de setembro de 2015, na região central da cidade, junto aos moradores de Registro, sendo desenvolvida em duas etapas. A primeira etapa da pesquisa consistiu-se em uma amostra piloto de 40 questionários a partir da qual foi possível estimar 0 tamanho da amostra final cujo, para um erro máximo de $10 \%$ e $95 \%$ de probabilidade, foi estimada em 88 questionários, dessa forma, na segunda etapa foram aplicados mais 48 questionários. Os questionários foram preenchidos pelo entrevistador nos pontos de maior circulação comercial na própria sede do município.

A análise estatística consistiu em realizar as medidas descritivas fazendo uso de tabelas de frequências e medidas de tendência central e dispersão, testes de comparação de médias, testes de independência de qui-quadrado obtidos mediante simulação de Monte Carlo, e testes de concordância estimadas pelo estatística W de Kendall.

Foi realizada uma análise multivariada de dados, mediando o uso de análise fatorial em componentes principais, conforme descrito por Hair et al. (2009) com as variáveis que descrevem a percepção sobre a arborização e as de gênero, idade e escolaridade. A utilização dessa técnica, ainda segundo esses autores, permite verificar quais as variáveis contribuem para melhor explicar a variabilidade dos dados bem como das relações existentes elas.

Para verificar se a distribuição da escolaridade dos respondentes apresentasse distribuição diferente entre os gêneros podendo neste caso gerar um viés nas análises foi realizado um teste de qui-quadrado, conforme descrito por Ferrán Aranaz (2011). Com o mesmo objetivo as idades entre os gêneros foram analisadas utilizando-se para tanto o teste de comparação de média de t de Student.

Como forma de aprofundar a interpretação das relações existentes entre as variáveis que tratam da percepção da arborização em seus mais diversos aspectos com as variáveis relacionadas a sexo, educação e idade foi realizada uma análise fatorial em componentes principais, técnica esta que consiste identificar variáveis representativas, fornecendo uma visão muito direta das inter-relações entre variáveis e respondentes, fornecendo uma clara compreensão sobre quais variáveis podem atuar conjuntamente e quantas destas podem ser consideradas como importantes na análise. 
Uma vez que os componentes são extraídos por ordem de importância em explicar a variabilidade dos dados é possível destacar, dentro do conjunto das variáveis, aquelas que mais contribuíram para a dispersão total.

Para efeitos de interpretação e análise, conforme recomendado por Hair et al. (2009) foram analisadas as variáveis que apresentaram uma correlação ao eixo fatorial de pelo menos 0,60 , cujos resultados podem ser visualizados na (Tabela 3 ).

\section{RESULTADOS E DISCUSSÃO}

Considerando 88 munícipes que responderam ao questionário, esse se dividiram em $64,0 \%$ do sexo feminino e $36,0 \%$ do sexo masculino. Quanto à escolaridade, $68,6 \%$ possuíam no mínimo curso médio completo, com idade média de 39,0 anos com 18,9 anos de desvio padrão para homens e 36,7 anos de idade média para as mulheres com 15,6 de desvio padrão. Segundo Oliveira et al. (2017) o grau de escolaridade pode interferir na elaboração de sugestões para a melhoria da arborização dos municípios, ou seja munícipes que possuem maior grau de escolaridade entendem mais os benefícios da arborização, fato que foi observado em Registro onde há predominância de pessoas que completaram o ensino médio sobre as que realizaram pós-graduação oque refletiu no interesse em se plantar uma árvore por conta própria em apenas 22 pessoas $(48,9 \%)$.

O de teste de qui-dradrado que verificou a distribuição da escolaridade dos respondentes mostrou que não houve dependência entre essas variáveis ( $p$-valor 0,99 ), sendo que com o mesmo objetivo as idades entre gêneros foram verificadas com o teste de comparação de média de $\mathrm{t}$ de Student, cujo p-valor de 0,17 indicou não ser possível refutar a hipótese de igualdade entre elas (Tabela 1).

Tabela 1. Perfil dos entrevistados

Table 1. Profile of respondents

\begin{tabular}{ccccc}
\hline Variável & Masculino & Feminino & Total & p-valor \\
\hline Escolaridade & & & & \\
Fundamental Incompleto & 3 & 5 & 8 & $0,99(\mathrm{a})$ \\
Fundamental Completo & 2 & 5 & 7 & \\
Médio Incompleto & 4 & 8 & 12 & \\
Médio Completo & 12 & 17 & 29 & \\
Superior incompleto & 4 & 8 & 12 & \\
Superior completo & 4 & 9 & 13 & \\
Pós-graduação & 2 & 3 & 5 & \\
\hline Total & 31 & 55 & 86 & \\
\hline Idade & & & & \\
$n$ & 31 & 56 & & $0,17(\mathrm{~b})$ \\
Média & 38,97 & 36,68 & & \\
\hline Desvio-padrão & 18,85 & 15,56 & &
\end{tabular}

(a) qui-quadrado por aproximação de Monte Carlo

(b) Teste t de Student para duas médias independentes 
Os resultados quanto à existência ou não de uma árvore junto à moradia do respondente e se em algum momento já existiu uma árvore mostram que $51 \%$ dos entrevistados possuem uma árvore em sua residência, sendo que 37,8\% afirmaram que a árvore existente foi plantada por inciativa própria e 13,3\% foram plantadas pela prefeitura sendo que 48,9\% não foram plantadas pelos munícipes que responderam ao questionário. Esses dados mostram que uma parcela considerável das árvores existentes é produto de iniciativa de particulares, existindo nesse caso específico, o risco de execução da uma arborização inadequada uma vez que a cidade não apresenta um plano para a arborização.

A arborização urbana implantada de uma forma errada pode interferir diretamente na qualidade de vida das pessoas. Grande parte da população desconhece as distâncias e normas empregadas para o plantio de espécies nas cidades e isto pode atrapalhar o desenvolvimento das árvores, a condução e a manutenção das plantas. Segundo Souza et al. (2014) citam que ruas com menos de $14 \mathrm{~m}$ de largura, não devem apresentar arborização urbana ou devem receber somente plantas pequenas ou arvoretas (árvores com de menos de $5 \mathrm{~m}$ de altura), sendo que as ruas com mais de $14 \mathrm{~m}$ de largura, com recuo uniforme, podem ser adornadas com árvores de porte médio (até $10 \mathrm{~m}$ de altura) de lado apropriado para sombreamento de pedestres, veículos e residências e para a arborização de ruas, especialmente onde há fiação elétrica, deve ser priorizada espécies de pequeno porte com mudas com até $5 \mathrm{~m}$ de altura. Estes dados citados por Souza et al. (2014) baseou-se no manual da Companhia Energética de São Paulo (CESP) de 1988 diz respeito e atendem as necessidades das cidades do estado.

Essa situação fica clara ao se analisar os resultados do motivo de retirada das árvores existentes $(7,0 \%)$, na qual apenas um respondente afirmou que a retirada da árvore se deu por morte da mesma, com as demais respostas estando diretamente relacionada à inadequação da espécie já que 44,3\% acreditam que as árvores aumentam a sujeira causada por pássaros e $30,7 \%$ revelaram que as mesmas podem causar problemas com os fios da rede elétrica (Tabela 2). Soares, Alves e Targino (2017) constataram que a arborização urbana, quando implantada de forma inadequada nas vias públicas, afeta o nível de mobilidade de pessoas principalmente aquelas com deficiência visual.

Das razões alegadas para a inexistência de uma árvore na calçada $(42,0 \%)$ as principais se relacionam ao fato destas "atrapalharem" a calçada, residência ou ambos que totalizam 45,9\% das respostas, resultados esses que demonstram a existência de um conhecimento prévio de arborizações inadequadas nas quais as árvores implantadas realmente podem atrapalhar e prejudicar calçadas e residências. Os dados apontados estão muito próximos do observado por Lourenço (2017) que ao perguntar para 100 moradores de São João Del-Rei em Minas Gerais se os mesmos plantariam uma árvore, 61,0\% dos entrevistados concordaram em ter alguma espécie de árvore na calçada de sua residência contra 39,0 \% não concordaram em plantar, 
dizendo que não havia espaço suficiente ou que já tiveram algum transtorno com árvores próximas a suas casas. Isto se deve pela falta de conhecimento das espécies ou mesmo por questões arquitetônicas da própria cidade, onde em muitas localidades as calçadas são estreitas, próximas das construções ou mesmo não há calçamento.

Um aspecto importante detectado nas respostas foram as razões dadas para as pessoas plantarem uma árvore em frente à própria residência. Dos quinze que afirmaram Não para essa questão, 66,7\% afirmaram que não o fariam, pois entendem que as árvores quebram a calçada ou atrapalham, sendo fonte de sujeiras e apenas $26,7 \%$ informaram a falta de tempo, sendo que um $6,6 \%$ não respondeu de forma correta o questionário.

Alternativamente, das 54 pessoas que afirmaram Sim, as principais razões para isso, $42,6 \%$ se relacionavam ao bem-estar proporcionado por uma árvore, tais como a melhoria do ar e redução do calor; 25,9\% à beleza, através das flores e melhoria da estética da cidade; e 11,6\% que enxergam no ato de plantar uma árvore como uma forma de ajudar a natureza, com os restantes divididos entre o gostar de árvores e outras razões não especificadas. Ho et al. (2015) registraram que $95 \%$ dos entrevistados gostariam de adotar uma árvore em frente sua casa ou estabelecimento, protegendo assim as mesmas contra o vandalismo e despendendo os cuidados necessários, estabelecendo assim um ato de cidadania.

A percepção do bem-estar proporcionado é claro, uma vez que a grande maioria dos respondentes $(59,3 \%)$ manifestam opinião favorável a arborização, o que realça a percepção positiva de uma arborização adequada para a cidade no que diz respeito a qualidade de vida, já que $48,0 \%$ e $38,0 \%$ citaram sombra e redução de calor como os principais itens citados como vantagens pelos entrevistados.

Os resultados da pesquisa univariada de percepção, estruturada com base na escala Likert, bem como o resultado de W de Kendall são apresentados na (Tabela 2). Cada uma das afirmações avaliadas pelos participantes está relacionada com os fatores que influenciam na opinião sobre a arborização existente. 
Tabela 2: Opinião sobre arborização urbana

Table 2: Opinion on urban afforestation

\begin{tabular}{|c|c|c|c|c|c|c|c|}
\hline Perguntas & A & $\mathrm{B}$ & C & D & $E$ & $\mathrm{~F}$ & Total \\
\hline A sua rua é bem arborizada? & 26 & 4 & 34,5 & 9 & 48 & 65,5 & 87 \\
\hline $\begin{array}{c}\text { Você considera que a cidade seja bem } \\
\text { arborizada? }\end{array}$ & 30 & 16 & 52,3 & 13 & 29 & 47,7 & 88 \\
\hline As árvores proporcionam sombra? & 67 & 15 & 93,2 & 4 & 2 & 6,8 & 88 \\
\hline $\begin{array}{l}\text { Você considera que as árvores sujam ruas e } \\
\text { calçadas? }\end{array}$ & 38 & 13 & 58 & 9 & 28 & 42 & 88 \\
\hline Árvores reduzem o calor? & 73 & 10 & 94,3 & 3 & 2 & 5,7 & 88 \\
\hline $\begin{array}{l}\text { Você acha que as árvores aumentam a sujeira } \\
\text { causada por pássaros? }\end{array}$ & 34 & 15 & 55,7 & 9 & 30 & 44,3 & 88 \\
\hline As árvores embelezam a cidade com flores? & 74 & 11 & 96,6 & 1 & 2 & 3,4 & 88 \\
\hline $\begin{array}{l}\text { Arvores podem ser responsáveis por } \\
\text { problemas de segurança? }\end{array}$ & 27 & 16 & 48,9 & 13 & 32 & 51,1 & 88 \\
\hline $\begin{array}{l}\text { As árvores das ruas devem proporcionar } \\
\text { frutos? }\end{array}$ & 32 & 20 & 59,1 & 11 & 25 & 40,9 & 88 \\
\hline $\begin{array}{l}\text { Árvores das ruas causam problemas com fios } \\
\text { da rede elétrica? }\end{array}$ & 42 & 19 & 69,3 & 10 & 17 & 30,7 & 88 \\
\hline $\begin{array}{l}\text { Árvores causam problemas com levantamento } \\
\text { de calçadas? }\end{array}$ & 44 & 13 & 64,8 & 15 & 16 & 35,2 & 88 \\
\hline $\begin{array}{l}\text { Árvores podem causar problemas com } \\
\text { circulação de pedestres? }\end{array}$ & 26 & 10 & 40,9 & 18 & 34 & 59,1 & 88 \\
\hline $\begin{array}{l}\text { Se existisse uma árvore em frente à sua casa } \\
\text { você a retiraria? }\end{array}$ & 11 & 13 & 27,3 & 6 & 58 & 72,7 & 88 \\
\hline
\end{tabular}

A. Corcordo, B. Concordo na maior parte, C. \%Concordância, D. Discordo na maior parte, E. Discordo, F. \% Discordância W de Kendall $=0,243 p$-valor $<0,001$

O resultado de $\mathrm{W}$ de Kendall $=0,243$ ( $\mathrm{p}$-valor $<0,001$ ) indica que as opiniões obtidas a partir da escala de Likert para o conjunto dos respondentes apresentam similaridades que são comuns a todos, isto é para cada uma das perguntas houve uma concordância de opinião entre os respondentes.

No conjunto os dados mostram que os respondentes têm uma percepção altamente positiva quanto aos benefícios da arborização. Ao se analisar as opiniões concordantes com as discordantes somadas, temos que mais de $90,0 \%$ das respostas estão no sentido de concordar que as árvores produzem sombra, reduzem o calor e embelezam a cidade com flores, havendo uma opinião majoritária em discordar $(59,1 \%)$ que as árvores possam causar problemas com a circulação de pedestres. Ao mesmo tempo, tem-se que 72,7\% discordam em retirar uma árvore caso ela existisse em frente à residência, número esse que representa um indicador altamente positivo quanto à receptividade a um programa adequado de arborização. $O$ alto índice das pessoas que discordam em retirar uma árvore em frente sua residência poderá ajudar em futuros programas de arborização urbana e planejamento árvore para cidade, pois os munícipes que têm árvores em casa são favoráveis as mesmas diante de suas residências.

Com relação a sombreamento e embelezamento da cidade estes dados estão de acordo com os observados por Novais et al. (2017) que registraram na cidade de Santana na Paraíba, $86,0 \%$ de aprovação das árvores com relação ao sombreamento, 31,0\% com relação a beleza 
estética e 28,0\% por preservar as questões ambientais como fatores negativos em $57,0 \%$ redes elétrica e telefônicas, sujeira de ruas e calçadas com 35,0\%. Os dados observados no presente estudo apontam para um problema nacional observado que é a ação das empresas elétrica e de telefonia, a população sabe dos benefícios, que a árvore, porém cita que a rede elétrica e de telefonia são um dos principiais problemas para a manutenção das árvores no meio urbano.

Os principais problemas apontados como concordantes se referem à problemas com a rede elétrica $(69,3 \%)$, levantamento de calçadas $(64,8 \%)$, sujeira da própria árvore $(58,0 \%)$, sujeira causada por pássaros (55,7\%), não havendo uma opinião majoritária quanto ao fato das árvores serem apontadas como um problema de segurança.

Quanto à arborização, a percepção de que a cidade seja bem arborizada foi de apenas $52,3 \%$, ao passe que $65,5 \%$ consideram não concordaram com a afirmação que a rua de moradia fosse bem arborizada. Para a arborização urbana acontecer na localidade, é necessário conhecer bem o local a ser implantado o projeto e não apenas plantar árvores na localidade. Maia et al. (2017) citam que é necessário realizar o planejamento da implantação com um bom trabalho de educação ambiental objetivando mostrar à população à importância da arborização no espaço urbano.

Da análise fatorial foi possível reter 6 fatores que, em conjunto explicam explicaram $60,6 \%$ da dispersão dos dados as quais foram interpretadas como se segue a seguir.

À primeira componente, com um poder de explicação de 18,8\%, ficaram correlacionadas as variáveis relativas aos problemas que as árvores podem causar, quais sejam:

a) As árvores das ruas causam problemas com fios da rede elétrica;

b) Você acha que as árvores aumentam a sujeira causada por pássaros

c) Árvores causam problemas com levantamento de calçadas

d) Você considera que as árvores sujam ruas e calçadas 
Tabela 3. Matriz de componentes fatoriais

Table 3. Factor components matrix

\begin{tabular}{|c|c|c|c|c|c|c|}
\hline \multirow{2}{*}{ Variáveis } & \multicolumn{6}{|c|}{ Componente } \\
\hline & 1 & 2 & 3 & 4 & 5 & 6 \\
\hline $\begin{array}{l}\text { As árvores das ruas causam problemas com fios } \\
\text { da rede elétrica }\end{array}$ & 0,78 & 0,05 & $-0,18$ & $-0,16$ & 0,15 & $-0,11$ \\
\hline $\begin{array}{l}\text { Você acha que as árvores aumentam a sujeira } \\
\text { causada por pássaros }\end{array}$ & 0,76 & 0,20 & 0,21 & $-0,04$ & $-0,04$ & 0,09 \\
\hline $\begin{array}{l}\text { Árvores causam problemas com levantamento de } \\
\text { calçadas }\end{array}$ & 0,72 & 0,08 & $-0,29$ & 0,01 & 0,08 & $-0,22$ \\
\hline $\begin{array}{l}\text { Você considera que as árvores sujam ruas e } \\
\text { calçadas }\end{array}$ & 0,65 & 0,24 & 0,22 & 0,17 & $-0,17$ & 0,40 \\
\hline $\begin{array}{l}\text { Árvores podem ser responsáveis por problemas de } \\
\text { segurança }\end{array}$ & 0,51 & 0,33 & 0,26 & 0,06 & 0,05 & 0,22 \\
\hline $\begin{array}{l}\text { Se existisse uma árvore em frente à sua casa você } \\
\text { a retiraria }\end{array}$ & 0,16 & 0,73 & $-0,02$ & 0,02 & 0,04 & $-0,07$ \\
\hline $\begin{array}{l}\text { Árvores podem causar problemas com circulação } \\
\text { de pedestres }\end{array}$ & 0,40 & 0,65 & $-0,03$ & $-0,01$ & 0,10 & $-0,27$ \\
\hline As árvores embelezam a cidade com flores & $-0,14$ & $-0,60$ & 0,16 & 0,27 & 0,12 & $-0,32$ \\
\hline Possui árvore na calçada & $-0,19$ & 0,07 & $-0,75$ & $-0,06$ & $-0,09$ & 0,10 \\
\hline Você considera que a cidade seja bem arborizada & $-0,22$ & 0,03 & 0,71 & $-0,18$ & $-0,09$ & $-0,13$ \\
\hline A sua rua é bem arborizada. & $-0,01$ & $-0,24$ & 0,52 & $-0,42$ & 0,24 & 0,12 \\
\hline Árvores reduzem o calor & 0,13 & $-0,31$ & 0,13 & 0,71 & $-0,25$ & $-0,08$ \\
\hline As árvores proporcionam sombra & $-0,10$ & $-0,07$ & $-0,22$ & 0,62 & 0,09 & 0,12 \\
\hline Idade & 0,05 & $-0,38$ & 0,06 & $-0,60$ & $-0,25$ & $-0,15$ \\
\hline Escolaridade & 0,25 & $-0,14$ & $-0,13$ & 0,08 & 0,68 & $-0,10$ \\
\hline $\begin{array}{l}\text { Quem você julga responsável por manter as } \\
\text { árvores da cidade bem cuidadas }\end{array}$ & 0,24 & $-0,27$ & $-0,14$ & $-0,14$ & $-0,65$ & 0,03 \\
\hline As árvores das ruas devem proporcionar frutos & 0,1 & 0,02 & 0,14 & $-0,28$ & 0,53 & 0,26 \\
\hline Gênero & $-0,03$ & $-0,07$ & $-0,17$ & 0,10 & 0,05 & 0,75 \\
\hline Variância total do componente (\%) & 18,8 & 11,7 & 8,6 & 7,9 & 7,2 & 6,4 \\
\hline Variância acumulada (\%) & 18,8 & 30,5 & 39,1 & 47,0 & 54,2 & 60,6 \\
\hline
\end{tabular}

A interpretação desse fator está na direção de que, o conjunto dessas opiniões negativas não surge dissociado, isto é, aparece como opiniões interligadas, nesse sentido um programa de arborização com base nessas percepções deve atender conjuntamente esses fatores, cuidado com a rede elétrica, sujeira e levantamento de calçada. Para Bobrowski e Biondi (2017) o conhecimento da morfometria de espécies florestais plantadas nas calçadas possibilita caracterizar a viabilidade das espécies de sua forma além das diferenças de conformação de copas. O conhecimento de tal índices morfométricos mostram-se aplicáveis como ferramenta auxiliar do manejo e planejamento da arborização de ruas, por expressarem. conformações e alterações das características naturais de crescimento das espécies.

O segundo componente (com 11,7\%) mostra três variáveis correlacionadas. Duas na mesma direção, "Se existisse uma árvore em frente à sua casa você a retiraria" e "Árvores podem causar problemas com circulação de pedestres", em oposição à variável "As árvores embelezam a cidade com flores". Fica claro nessa componente a percepção de que, uma vez implantada 
uma árvore que venha a atrapalhar a circulação de pedestres essa terá uma grande chance de ser removida. Alternativamente, os respondentes que consideram que as árvores embelezam a cidade apresentam uma preocupação menor quanto ao aspecto das árvores serem um empecilho à circulação.

Ao analisar-se o terceiro componente, que representa 8,6\% da dispersão observada, encontramos duas variáveis em oposição, "Possui árvore na calçada" e "Você considera que a cidade seja bem arborizada" essa relação deixa claro que a percepção de uma arborização urbana passa pela existência, ou não, de uma árvore na calçada do respondente em um sentido de que, quem possui uma árvore na calçada não considera a cidade bem arborizada. A percepção de ter ou não uma árvore na calçada contribui muito pouco na escolha das espécies ideais por parte dos munícipes de uma cidade.

Ferraz (2012) ao estudar as espécies da cidade de Registro em São Paulo, notou que muitas apresentavam afloramento das raízes nas calçadas, o que em grande parte dos casos, impedia a passagem de pedestres e cadeirantes, refletindo assim pouca preocupação dos munícipes em se fazer a descompactação do solo durante o plantio bem como nenhuma preocupação na escolha das árvores corretas para o plantio.

Quando verificamos o quarto componente (7,9\% de explicação) constatamos uma relação inversa entre as variáveis que associam sombra e redução de calor à idade do respondente. A análise mostra uma na qual as pessoas mais velhas valorizam e percebem positivamente esses aspectos, ao passo que os mais jovens não consideram isso tão importante. $O$ fato da arborização urbana estar relacionada com a temperatura também foi estudado por Costa, Bezerra e Freire (2013) que ao perguntarem para seus entrevistados (independente da idade) sobre as vantagens que arborização urbana proporciona sob o meio ambiente urbano, pouco mais de $53,6 \%$ afirmaram que o principal benefício da arborização urbana está relaciona com o controle da temperatura.

O quinto fator, que acumula um poder explicativo de $7,2 \%$ da variabilidade total, apresenta como variáveis correlacionadas "Quem você julga responsável por manter as árvores da cidade bem cuidadas" com "Escolaridade". A análise dos dados originais mostra uma tendência no sentido de que, quanto menor a escolaridade maior a tendência de responsabilizar o poder público por essa questão, na medida em que a escolaridade aumentar existe uma indicação que o proprietário, de forma compartilhada com o poder público sejam responsáveis por essa manutenção. Para Sufia, Souza e Siqueira (2018) pesquisar o grau de escolaridade é um fator importante para identificar a correlação do nível de instrução dos munícipes com a percepção da arborização urbana.

Finalmente, o sexto componente que, em conjunto com os demais acumula $60,6 \%$ da variância total, tem como variável correlacionada "Gênero". A presença de uma única variável 
correlacionado ao componente é indicador da inexistência de variáveis associadas ao sexo, fato esse confirmado pela análise de qui-quadrado que mostrou que as respostas para todas as variáveis relacionadas à percepção foram independentes do sexo.

\section{CONCLUSÕES}

Constatou-se que os moradores de Registro em São Paulo, têm nível médio de escolaridade, portanto compreendem e entendem os benefícios da arborização urbana, porém o risco de erro na arborização é alto uma vez que a população planta a própria planta sem nenhum planejamento por parte dos órgãos competentes.

Verificou-se que um grande trabalho de conscientização deve ser feito com as elétricas e a prefeitura municipal para melhorar os projetos de arborização e a manutenção das árvores, ja que fica claro que a cidade não tem nenhum trabalho neste sentido sendo realizado.

\section{REFERÊNCIAS}

BOBROWSKI, R.; BIONDI, D. Morfometria de espécies florestais plantadas nas calçadas. Revista da Sociedade Brasileira de Arborização Urbana, Piracicaba, v.12, n.1, p. 01-16, 2017.

BRANDÃO, H. P.; BAHRY, C. P. Gestão por competências: métodos e técnicas para mapeamento de competências. Revista do Serviço Público, Brasília, v. 56 n. 2 p.179-194, 2005.

COSTA, C.G.F.; BEZERRA, R.F. e FREIRE, G.S.S. Avaliação da percepção da arborização urbana em Fortaleza. Revista da Sociedade Brasileira de Arborização Urbana. Piracicaba, v.8, n.4, p 73-88, 2013.

FERRÁN ARANAZ, M. SSPS para Windows: análisis estadístico. Madrid: Mc Graw-Hill, 2011.

FERRAZ, M. V. Inventário das árvores urbanas da cidade de Registro-SP. Revista da Sociedade Brasileira de Arborização Urbana, Piracicaba, v.7, n.2, p.80-88, 2012.

FERRAZ, M. V., NOGUEIRA, D. M. Arborização Urbana Para o Município de Registro-SP. IN: Workshop Sobre Arborização Urbana do Vale do Ribeira, 1., 2009, Registro. Anais do I Workshop Sobre arborização Urbana do Vale do Ribeira. Registro; Botucatu: FEPAF, 2009. $68-81$.

HAIR Jr., J.F.; BLACK, W.C.; BABIN, B.J.; ANDERSON, R.E. \& TATHAM, R.L. Análise multivariada de dados. 6.ed. Porto Alegre, Bookman, 2009. 688p. 
HO, T. L.; KOVALSYKI, B.; BIONDI, D. Percepção dos moradores sobre a arborização de ruas da região central de Mandirituba/PR. Revista da Sociedade Brasileira de Arborização Urbana, Piracicaba, v.10, n.3, p. 14-23, 2015

Instituto Brasileiro de Geografia Estatística (IBGE). IBGE Cidades e Estados. Disponível em: <https://www.ibge.gov.br/cidades-e-estados/sp/registro.html> Acesso em: 17 set. 2019.

LOURENÇO, J.S.G. Percepção Da População Sobre a Arborização da Cidade de São João DelRei, MG. Revista da Sociedade Brasileira de Arborização Urbana, Piracicaba, v.12, n.2, p. 62-72, 2017.

LOURENÇO, L. F. A.; MOREIRA, T. C. L.; ARANTES, B.L.; SILVA FILHO, D. F.; MAUAD, T. Metrópoles, cobertura vegetal, áreas verdes e saúde. Estudos Avançados, São Paulo, v. 30, n. 86, p. 113-130, 2016.

MAIA, L.P.S.S.; OLIVEIRA, E.D.; SANTOS, M.O.; CELLA, W. Estudo da Percepção Ambiental sobre Arborização Urbana no Bairro Fonte Boa, Tefé-Amazonas, Brasil. Revista da Sociedade Brasileira de Arborização Urbana, Piracicaba, v.12, n.2, p. 48-61, 2017.

MARIA, T. R. B. C.; BIONDI, D.; BROBOWSKI, R. Qualitative and quantitative floristic inventory of street trees in Itanhaém-SP. Revista Brasileira de Arborização Urbana, Piracicaba, v.11, n. 4, p. 79-97, 2016.

NOVAIS, D.B.; SOUTO, P.C.; BARROSO, R.F. CAMAÑO, J.D.Z.; FERREIRA, V.S.G. Arborização na cidade de Santa Helena na Paraíba: A percepção dos seus munícipes. Revista da Sociedade Brasileira de Arborização Urbana, Piracicaba, v.12, n.1, p. 31-45, 2017

OLIVEIRA, V. P.; DIAS, J. G. S.; RIBEIRO, A. T.; OLIVEIRA, L. B. S.; MARIANO, M. O.; PINTO, D. S. A Percepção da População sobre Arborização Em um Conjunto Habitacional No Município De Paragominas-PA. Revista da Sociedade Brasileira de Arborização Urbana, Piracicaba, v.12, n.3, p. 27-36, 2017.

PEREIRA, J.C.R. Análise de dados qualitativos: estratégias metodológicas para as ciências da saúde, humanas e sociais. [S. I: s.n.], 2004.

RECH, M; MARTINS, E. M. Desenvolvimento de um sistema de gerenciamento da arborização urbana para o município de Caxias do Sul, RS. Revista da Sociedade Brasileira de Arborização Urbana, Piracicaba, v.11, n.4, p. 115-129, 2016.

RODRIGES, T. D.; MALAFAIA, G.; QUEIROZ, E. E. Percepção sobre arborização urbana de moradores em três áreas de Pires do Rio - Goiás. REA - Revista de estudos ambientais (Online) Goiás, v.120, n. 20, p. 47-610, 2010

SILVA, K. A. R.; LELES, P. S. S.; GIÁCOMO, R. G.; MENDONÇA, B. A. F. Diagnóstico e uso de geoprocessamento para manejo da arborização urbana do bairro centro da cidade do Rio de Janeiro - RJ. Revista da Sociedade Brasileira de Arborização Urbana, Piracicaba, v.11, n.4, p. $98-114,2016$.

SOARES, A.M.J.; ALVES, R. L.; TARGINO, E.N.M.A. Acessibilidade na Arborização Urbana: Percepção de Deficientes Visuais sobre a Mobilidade em Espaços Públicos Arborizados. Revista da Sociedade Brasileira de Arborização Urbana, Piracicaba, v.12, n.3, p. 51-65, 2017. 
SOUZA, P. F.; BOURSCHEID, C. B.; POMPÉO, P. N.; STANG, M. B.; MANFROI, J.; RODRIGUES, M. D. S.; SILVA, A. C.; HIGUCHI, P. Inventário e recomendações para a arborização do centro da cidade de São Joaquim, SC. Revista da Sociedade Brasileira de Arborização Urbana, Piracicaba, v.9, n.4, p 99-112, 2014.

SUFIA, M.C.S.; SOUZA, G.S.; SIQUEIRA, M.V.B.M. Percepção ambiental sobre arborização urbana em regiões distintas do município de Bauru-SP. Revista da Sociedade Brasileira de Arborização Urbana, Curitiba, v.13, n.4, p. 15-28, 2018

TONETTI, A. M.; BIONDI, D.; LEITE, J. C. M. Perfil dos usuários de áreas verdes de Curitiba e a sua percepção sobre a capivara (Hydrochoerus hydrochaeris L.). Revista da Sociedade Brasileira de Arborização Urbana, Piracicaba, v.11, n.4, p. 47-65, 2016.

WANDERLEY, R.J.C.; PEREZ, C.A.M.; REBÊLO, D.; SOUZA, P.A. GIONGO, M.; SANTOS, A.F. Estudo quali-quantitativo e percepção ambiental da arborização do setor Jardim Sevilha, Gurupi - TO. Revista da Sociedade Brasileira de Arborização Urbana, Piracicaba, v.12, n.4, p. 5368, 2017.

ZEM, L. M.; BIONDI, D. Análise da percepção da população em relação ao vandalismo na arborização viária de Curitiba - PR. Revista da Sociedade Brasileira de Arborização Urbana, Piracicaba, v. 9, n. 3, p. 86-107, 2014. 